\title{
SAFE EX VIVO CORONARY ANGIOGRAPHY WITH ISOSMOTIC CONTRAST AGENT
}

Donald B. Schmit, MD

John A. Kern, MD

Michael C. Mauney, MD

Irving L. Kron, MD

Curtis G. Tribble, MD
Plain-film coronary angiography of the cardiac explant on the operating table should be considered when conventional cardiac catheterization is desired but unavailable. We compared the effects of three contrast solutions on cold-preserved, isolated guinea pig hearts. Hearts were excised, perfused for 30 minutes, and arrested with Plegisol solution at $7^{\circ} \mathrm{C}$. Twenty minutes after arrest, experimental hearts were perfused with one of three solutions: hyperosmolar Hexabrix solution $(n=6)$, hyperosmolar Renografin-76 solution $(n=6)$, or diluted, isosmotic Omnipaque solution $(n=8)$. The hearts were flushed with cold Plegisol solution 5 minutes later. Control hearts received no contrast during arrest $(n=9)$. The hearts were reperfused after 1 hour of arrest, and coronary blood flow (in millimeters per minute), left ventricular developed pressure (in millimeters of mercury), and rate of developed pressure (in millimeters of mercury per second) were measured. Endothelium-dependent smooth muscle relaxation to bradykinin administration and endothelium-independent relaxation to sodium nitroprusside administration were also assessed. No significant difference in myocardial or endothelial function was noted between control hearts and hearts perfused with Omnipaque solution. Hearts perfused with Renografin solution or Hexabrix solution, however, were found to have significantly impaired endothelial and myocardial function. We conclude that an isosmotic contrast solution should be used for ex vivo coronary angiography in cold-preserved hearts to avoid impairment of endothelial and myocardial function. (J Thorac Cardiovasc Surg 1996;112:306-9)
$\mathrm{B}_{\mathrm{c} a}^{\mathrm{e}}$ ecause of the inadequate supply of donors for cardiac transplantation it has become necessary for transplant programs to liberalize donor selection criteria. One area in which liberalization has occurred is the use of older heart transplant donors. ${ }^{1}$ Concomitant with the increased age of these potential donors is the increased risk of coronary artery disease. Although cardiac catheterization of donors before organ harvesting can identify significant coronary artery disease, we have recently encountered situations in which older donors have become available in hospitals that lack cardiac catheterization ca-

From the University of Virginia Health Sciences Center, Charlottesville, $\mathrm{Va}$.

Received for publication June 22, 1995; accepted for publication Oct. 16, 1995.

Address for reprints: Curtis G. Tribble, MD, University of Virginia, Department of Surgery, Health Sciences Center Box 181, Charlottesvile, VA 22908.

Copyright (C) 1996 by Mosby-Year Book, Inc.

$0022-5223 / 96 \$ 5.00+0 \quad \mathbf{1 2 / 1 / 6 9 9 5 0}$ pabilities. Occasionally, families of these donors refuse to allow the donor to be transported to a suitably equipped facility. This decision can leave the transplant team with the difficult task of deciding whether or not to accept the heart on the basis of inadequate information about the coronary circulation.

Techniques for ex vivo coronary angiography have been described by Robicsek ${ }^{2}$ and Lee and their associates. ${ }^{3}$ Both groups found that the ionic, high-osmolar contrast solutions that they used demonstrated no impairment of postarrest myocardial function. Their studies, however, made no assessment of coronary endothelial function. We have shown in a previous study that preservation of endothelial function is an important determinant of ventricular recovery after ischemia. ${ }^{4}$ The goal of this study was to identify a contrast solution that would cause minimal impairment of ventricular and endothelial function in an effort to further the development of a simple and safe method of ex vivo visualization of donor coronary arteries. 
Table I. Comparison of contrast solutions used

\begin{tabular}{lc}
\hline \multicolumn{1}{c}{$\begin{array}{c}\text { Contrast } \\
\text { solution }\end{array}$} & $\begin{array}{c}\text { Approximate osmolality, } \\
\text { ionicity }\end{array}$ \\
\hline Dilute (37 vol\%) Omnipaque 350 & $280 \mathrm{mOsm} / \mathrm{kg} \cdot \mathrm{H}_{2} \mathrm{O}$, nonionic \\
Full-strength Hexabrix & $600 \mathrm{mOsm} / \mathrm{kg} \cdot \mathrm{H}_{2} \mathrm{O}$, ionic \\
Full-strength Renografin & $1700 \mathrm{mOsm} / \mathrm{kg} \cdot \mathrm{H}_{2} \mathrm{O}$, ionic \\
\hline
\end{tabular}

\section{Material and methods}

Three different contrast solutions were chosen for various reasons. Renografin solution, the least expensive of the three, represents the most economical alternative. Hexabrix solution was tested and thought to be safe by previous investigators. ${ }^{2}$ Omnipaque solution has the lowest osmolality at full strength and has the added advantage of being the only nonionic solution used. Table I illustrates the approximate osmolality of the three contrast solutions used.

All animals received humane care in compliance with the "Principles of Laboratory Animal Care" formulated by the National Society for Medical Research and the "Guide for the Care and Use of Laboratory Animals" prepared by the Institute of Laboratory Animal Resources of the National Institutes of Health (NIH Publication No. 86-23, revised 1985).

Twenty-nine guinea pigs ( 300 to $350 \mathrm{gm}$ ) were anesthetized with intraperitoneal injections of ketamine $(60 \mathrm{mg} /$ $\mathrm{kg})$ and xylazine $(6 \mathrm{mg} / \mathrm{kg})$ and then paralyzed with metocurine $(0.2 \mathrm{mg} / \mathrm{kg}) 1$ minute later. Before respiratory arrest, the chest was opened, the trachea was intubated, and the lungs were mechanically ventilated. The hearts were rapidly excised and perfused with oxygenated KrebsHenseleit bicarbonate buffer ${ }^{5}$ under constant pressure $(60$ $\mathrm{cm} \mathrm{H}_{2} \mathrm{O}$ ) at $37^{\circ} \mathrm{C}$ with use of a modified Langendorff technique. ${ }^{6}$ Hearts were paced at $4 \mathrm{~Hz}$. The right side of the heart was decompressed through a cannula in the right ventricular outflow tract, and a fluid-filled latex balloon was placed in the left ventricle through the mitral valve orifice for measurements of left ventricular developed pressure (LVDP; in millimeters of mercury). Coronary blood flow (CBF; in milliliters per minute) was measured continuously with an in-line ultrasonic flow probe at the aortic root. Baseline measurements of CBF and LVDP were taken after 30 minutes of equilibration. All hearts were then arrested and preserved with cold Plegisol solution $\left(7^{\circ} \mathrm{C}\right)$ for 1 hour.

After 20 minutes of arrest, the experimental hearts were infused with one of three cold $\left(7^{\circ} \mathrm{C}\right)$ contrast solutions: (1) Omnipaque 350 solution $(n=8)$ diluted to an isosmotic solution ( $37 \mathrm{vol} \%$ ), (2) full-strength, hyperosmotic Hexabrix solution ( $n=6)$, and (3) full-strength, hyperosmotic Renografin solution $(n=6)$. A total of 10 $\mathrm{ml}$ of solution was infused at a rate equal to baseline CBF. To simulate the time required to obtain adequate radiographs, the contrast solution was flushed out with $20 \mathrm{ml}$ of cold Plegisol solution after 5 minutes. A group of control hearts did not receive any contrast solutions during arrest $(n=9)$.

At the completion of 1 hour of hypothermic arrest the hearts were reperfused with $37^{\circ} \mathrm{C}$ oxygenated KrebsHenseleit bicarbonate buffer. Postresuscitation measure-
Table II. Comparison of baseline and postresuscitation myocardial function

\begin{tabular}{|c|c|c|c|c|}
\hline & \multicolumn{2}{|c|}{$C B F(\mathrm{ml} / \mathrm{min})$} & \multicolumn{2}{|c|}{$L V D P(m m ~ H g)$} \\
\hline & Baseline & Postresuscitation & Baseline & Postresuscitation \\
\hline Control & $9 \pm 0.5$ & $9 \pm 0.5$ & $93 \pm 3$ & $95 \pm 5$ \\
\hline $\begin{array}{l}\text { Omnipaque } \\
\text { solution }\end{array}$ & $10 \pm 0.7$ & $10 \pm 0.5$ & $105 \pm 3$ & $100 \pm 2$ \\
\hline $\begin{array}{l}\text { Hexabrix } \\
\text { solution }\end{array}$ & $9 \pm 0.4$ & $7 \pm 0.9$ & $96 \pm 3$ & $51 \pm 9^{*}$ \\
\hline $\begin{array}{c}\text { Renografin } \\
\text { solution }\end{array}$ & $8 \pm 0.5$ & $4 \pm 0.3^{*}$ & $95 \pm 7$ & $21 \pm 1 *$ \\
\hline
\end{tabular}

${ }^{*} p<0.05$ versus control values, otherwise not significant; $t$ test (mean plus or minus standard error of mean).

ments of CBF and LVDP were obtained after 45 minutes of equilibration. Vasomotor responsiveness was assessed by measuring changes in CBF after administration of the endothelium-dependent vasodilator bradykinin $\left(1 \times 10^{-8}\right.$ $\mathrm{mol} / \mathrm{L})$ and the endothelium-independent vasodilator sodium nitroprusside $\left(1 \times 10^{-6} \mathrm{~mol} / \mathrm{L}\right)$. On termination of the studies, all hearts were weighed after both atria were removed. A $t$ test analysis was done on each set of data, comparing data from each contrast solution with data from the control group.

In addition, to determine how well coronary arteries are visualized when perfused with the diluted Omnipaque solution, explanted hearts from recently killed large dogs received selective coronary artery perfusions of $10 \mathrm{ml}$ of the diluted Omnipaque solution followed by a plain film roentgenogram. Radiographs were taken in the anteroposterior and left anterior oblique orientations at $12.5 \mathrm{~mA}$ and $70 \mathrm{kVp}$.

\section{Results}

Table II shows the baseline and postresuscitation values for CBF and LVDP for all four groups of hearts. There were no statistically significant differences in ventricular weight or in baseline CBF and LVDP values among the four groups. In addition, no differences in postresuscitation values existed between the control hearts and those hearts perfused with dilute Omnipaque solution. However, those hearts perfused with Hexabrix solution and Renografin solution showed significant impairment of postresuscitation LVDP compared with values in control hearts. The Renografin solution group displayed significantly decreased CBF values compared with those in control hearts.

Table III shows the postresuscitation vasomotor responses to bradykinin and sodium nitroprusside. Those hearts perfused with Hexabrix solution and Renografin solution showed significant reduction in endothelium-dependent and endothelium-independent vasodilators compared with control hearts. However, hearts perfused with diluted Omnipaque 


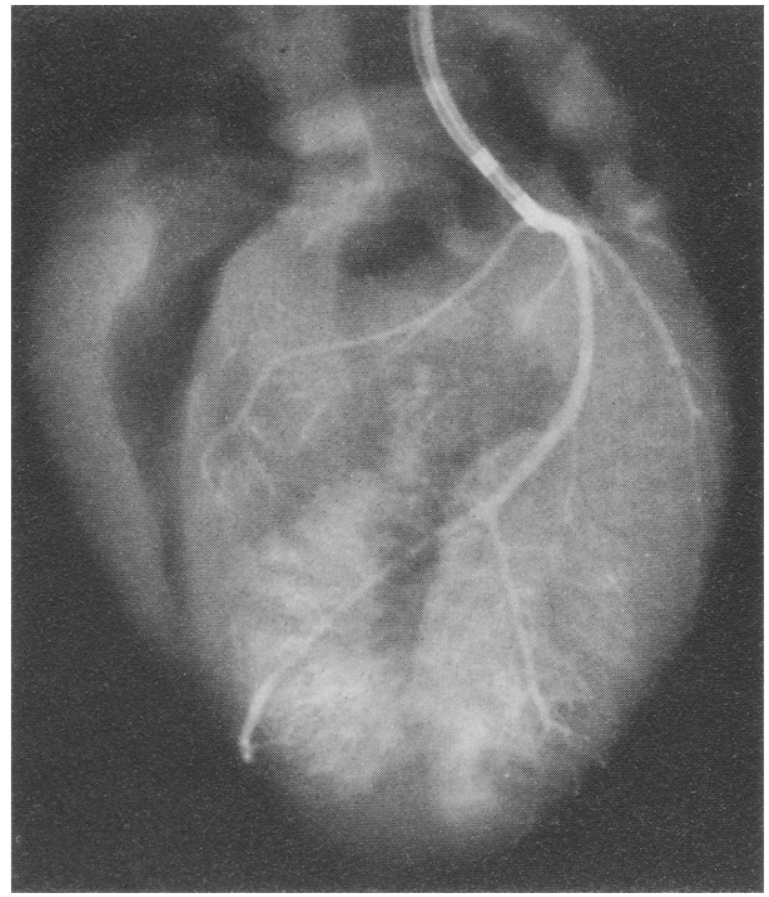

Fig. 1. Perfusion of isosmotic Omnipaque solution adequately visualizes coronary anatomy in an explanted canine heart.

solution maintained their responsiveness to both bradykinin and sodium nitroprusside. Finally, radiographs from the canine hearts perfused with Omnipaque solution revealed an adequate level of anatomic detail (Fig. 1).

\section{Discussion}

As is the case in other cardiac transplant programs, many donors evaluated by the University of Virginia transplant program come from areas served by small hospitals with limited facilities. We are often unable to arrange transportation to our hospital for purposes of donor evaluation. If the donor is young and healthy, the heart often can be harvested without further evaluation. However, the issue of latent coronary artery disease must be considered when an older organ donor is being evaluated.

To study the coronary anatomy at the site of harvest requires a technique that is quick, safe, and uses readily available equipment. The optimal technique would be one that does not cause myocardial or endothelial damage or dysfunction. Reports of techniques for ex vivo coronary angiography have suggested that normal postresuscitation cardiac function
Table III. Postarrest peak CBF in response to bradykinin and sodium nitroprusside

\begin{tabular}{lcc}
\hline & $C B F$ & $C B F$ \\
& $($ mllmin $)$ & (ml/min) \\
after $1 \times$ & $10^{-6}$ mol/L \\
$10^{-8}$ moll/ & sodium \\
bradykinin & nitroprusside \\
& $18 \pm 2.4$ & $14 \pm 1.3$ \\
Control & $15 \pm 1.9$ & $13 \pm 0.9$ \\
Omnipaque solution & $9 \pm 1.3^{*}$ & $8 \pm 1.1^{*}$ \\
Hexabrix solution & $4 \pm 0.3^{*}$ & $5 \pm 0.4^{*}$ \\
Renografin solution &
\end{tabular}

can return after use of full-strength, high-osmolality contrast solutions. ${ }^{2,3}$ However, no previous studies have assessed preservation of endothelial function after administration of contrast agents. Studies done in our laboratory have demonstrated that preservation of endothelial function is important to the postischemic function of cardiac allografts. ${ }^{4}$ The results of this study suggest that an isosmotic contrast solution is necessary if both myocardial and endothelial integrity are to be preserved. In contrast to the findings of Lee and associates, ${ }^{3}$ administration of high-osmolality ionic contrast solutions was associated with a significant reduction in ventricular function and impaired endothelial function.

Although technically superior methods of ex vivo coronary angiography have been described that use full-strength contrast solutions, ${ }^{2,3}$ these methods did not assess coronary anatomy with an isosmotic dilution of contrast solution. We wanted to be sure that coronary anatomy would still be visible with the dilute solution. Coronary arteries were easily visualized with isosmotic dilution of Omnipaque solution. Further work is needed, however, to adequately develop this technique for clinical application.

The technique of ex vivo coronary angiography has other advantages besides aiding in cardiac allograft suitability. By eliminating the need for preharvest cardiac catheterization, the risks of renal damage from contrast loads and cholesterol embolization to other organs are also eliminated. ${ }^{7,8}$ Furthermore, substantial cost reductions could be achieved if this form of plain-film coronary angiography were to become the standard of care for donor hearts in place of conventional cardiac catheterization.

In conclusion, we have demonstrated that ex vivo 
coronary angiography is safe and effective in animal models as long as isosmotic contrast solutions are used for the angiograms. The information gained, the elimination of risk to other donor organs, and potential cost savings of this technique warrant further investigation.

\section{REFERENCES}

1. Sweeney MS, Lammermeier DE, Frazier OH, et al. Extension of donor criteria in cardiac transplantation: surgical risk versus supply-side economics. Ann Thorac Surg 1990;50:7-11.

2. Robicsek F, Masters TN, Thomley AM, et al. Bench coronary cineangiography: a possible way to increase the number of hearts available for transplantation. J Thorac Cardiovasc Surg $1992 ; 103: 490-5$.

3. Lee CC, Aruny JE, Laurence RG, et al. Bench coronary angiography: a potentially useful method to assess coronary artery disease in the older donor heart without catheterization laboratory angiography. J Heart Lung Transplant 1992;11:693-7.

4. Kern JA, Cassada DC, Chan BBK, et al. Preservation of coronary endothelial function results in improved cardiac function following prolonged ischemic cardiac arrest. Surg Forum 1992;43:218-20.

5. Krebs HA, Henseleit K. Untersuchungen uber die Harnstoffbildung im Tierkorper. Hoppe Seylers Z Physiol Chem 1932; 210:33-66.

6. Langendorff $O$. Untersuchungen am uberlebenden Saugethierherven. Pflugers Arch 1895;61:291-332.

7. Ueda M, Fujimoto $\mathrm{T}$, Ogawa $\mathrm{N}$, et al. An autopsy case of cholesterol embolism following percutaneous transluminal angioplasty and aortography. Acta Pathologica Japonica 1989;39: 203-6.

8. Maunesse CK, Blankestijn PJ, Man in’t Veld AJ, et al. Renal failure and cholesterol embolization: a report of 4 surviving cases and a review of the literature. Clin Nephrol 1991;36:240-5.

\section{ON THE MOVE?}

Send us your new address at least six weeks ahead

Don't miss a single issue of the journal! To ensure prompt service when you change your address, please photocopy and complete the form below.

Please send your change of address notification at least six weeks before your move to ensure continued service. We regret we cannot guarantee replacement of issues missed due to late notification.

\section{JOURNAL TITLE:}

Fill in the title of the journal here.

\section{OLD ADDRESS:}

Affix the address label from a recent issue of the journal here.

\section{NEW ADDRESS:}

Clearly print your new address here.

Name

Address

City/State/ZIP
COPY AND MAIL THIS FORM TO: Journal Subscription Services Mosby-Year Book, Inc. 11830 Westline Industrial Dr. St. Louis, MO 63146-3318
OR FAX TO:

314-432-1158

N/M Mosby
OR PHONE:

1-800-453-4351

Outside the U.S., call

314-453-4351 